\title{
Developing a Sustainable Practical Model of Graduate Employability for Higher Education
}

\author{
Ahmed Umar Rufai (Corresponding author) \\ Faculty of Educational Studies, University Putra Malaysia, 43400 UPM Serdang Selangor Malaysia \\ E-mail: elrufaifarouk@gmail.com \\ Ab Rahim Bin Bakar \\ Faculty of Educational Studies, University Putra Malaysia, 43400 UPM Serdang Selangor Malaysia \\ Abdullah Bin Mat Rashid \\ Faculty of Educational Studies, University Putra Malaysia, 43400 UPM Serdang Selangor Malaysia
}

Received: 16-12- 2014

doi:10.7575/aiac.ijels.v.3n.1p.42
Accepted: 29-01-2015

URL: http://dx.doi.org/10.7575/aiac.ijels.v.3n.1p.42

Published: 30-01-2015

\begin{abstract}
The purpose of this paper is to evolve a sustainable practical model of employability skills that is sure to capture relevant learning aspects of a particular occupational discipline to be used as framework for Undergraduate students to develop their employability potentials. The study was conducted in three Universities and Polytechnics each with three multi-national companies. Data were collected using semi-structured interviews. Using purposeful sampling 18 academic staff and 3 professionals representing company employers were selected as the study participants. The study evolved a model that is work-based, explicit in its outcome, fully articulated and realistic in terms of employability skill experiences. The proposed model can be used to establish a common higher education programme or curricula that is work-based and skill experience oriented, that can encourage students in higher education to think about work place learning more explicitly and reflectively, that will in turn help them to develop a broad range of knowledge, skills, attitudes, and values, each of which ultimately contribute in some manner to graduate employability. The paper is considered a contribution to the evolution and growth of knowledge on the linkage between higher education and workplace, through which the 'skill gap' occurring between the demand of employment and the level of educational preparation of graduates can be bridged.
\end{abstract}

Keywords: Employability, Higher Education, Graduates, Model/Framework, academic staff, Employers/Professionals

\section{Introduction}

Employers of industries and related business organizations, professional bodies, Higher Institutions, including curriculum experts in Nigeria and elsewhere in the world agree that there is a need to develop professionals who are highly skilled and ready to face the challenges of increased competition. More than ever, we need professionals who are responsive to economic, social, cultural and technical environment change that can work flexibly and intelligently across business contexts.

Business and industry requires crop of graduates who understand their role in building their organizations and possess the practical skills to work effectively and efficiently in their roles. However, real contributions in the workplace means more than having the necessary technical skills. It means engaging with the organization and its goal, understanding the dynamics of the workplace, and taking up a job with an informed knowledge of all its requirements. It also means applying a broad range of employability skills learned in many contexts and through a range of experiences.

For any attempt by industries and business sectors aspiring to be more competitive, more effective and more innovative, one should realize that, the graduate workforce represent an important part of the talent pool that businesses draw from, and to further these objectives, tertiary institutions clearly need to produce graduates with the skills that are highly regarded by employers, while on the other hand, emerging professionals want to attain interesting employment and build their professional careers.

Many criticisms had been leveled on the institutions of higher learning, some of which were, that their products made little or no contribution to the economic and technological development. In particular, contributions of higher education graduates to the development of Business and Industries was far below expectations (Jen, 2002). The consensus was that the mode and nature of training in those institutions have little or no relevance to the social-economic needs of the labour market, he further observed. It appears that the original objectives of tertiary institutions as centers for generating innovative knowledge and personnel requisite for creating new production system, on the one hand, and graduates with skilled manpower to help in maintaining these system especially in industries, on the other hand, has been greatly compromised. In support of this assertions, evidences from literature (Yabani 1990); Oranu, 1991; Okoro, 1994; 
Olaitan, 1996; Njoku, 1997 Abubakar, 2002 suggests that the products of higher educational institutions are not meeting the needs of Business and Industry as a result of inadequate preparations in terms of skill acquisition.

Higher education at all levels was known to provide among other things that aspect of education which leads to the acquisition of practical skills as well as basic scientific knowledge NPE, (1998). Among its goals and objectives was the provision of technical knowledge and vocational skills necessary for industrial and economic development as well as provision of skill trained manpower in applied science, technology and commerce.

It was the attempt to meet these objectives, which led to the establishment of several other institutions of higher learning and they are given specific assignments to provide adequate competent and skill human resources at all levels of the economy. Consequently, many additional new courses were introduced and the curricula of the existing institutions were remarkably improved to meet the present day challenges. However, one has to realize the fact that for such programmes in the tertiary institutions to be wholly effective, students during their training must receive adequate skills that make them employable, and complementary to the courses they are studying; this will ensure that students have sufficient opportunities during their daily work to practice and develop their skills in applying techniques and procedures at their place of work (Fagbemi, 1988).

\subsection{Why Has Employability Become an Issue in Higher Education?}

In recent years, widening participation and the development and use of employability skills has increasingly become very crucial within the contemporary higher education throughout the world. The reason for such emphasis may not be unconnected with skill gap occurring between the demand of employment and the level of educational preparation of graduates, and of course, the manifestation of graduates open unemployment, opportunities for most students graduating from tertiary institutions, to mobilize their skills, talents and energies in the modern process is still yet to be achieved (Uwaifo, 2009). Merlin, (2007) points out that interest in employability has emerged as a result of the organizational and demographic changes. Employers tend to be looking for individuals who have the capacity to make an immediate and stable career path to sustain the current global system on the adequate supply of relevant and quality skill and competent manpower to man the various sectors of the economy. The dream of which is far from being achieved, as observed by Burk and $\mathrm{Ng}$, (2006), that one can argue that the declining birth rates and aging population are resulting in skill and labour shortages. This development has in recent times consistently increased the calls by employers of industries for employable skill personnel. This was also the view of Richardson (2006) that employers are finding it increasingly difficult to attract suitably skilled, qualified and experienced employees to meet their current demands as well as future growth needs.

This was by no means part of the consistent call on higher education to closely align their training programmes with work, and this has to some extent put higher institutions under intense pressure and a challenge to produce and equip graduates that are more ready for professional employment especially in areas of work-based skill competency, and not just the academic skills traditionally peculiar to subject discipline and or a class of degree. Lind, (2007) has this to say that the expansion of higher education participation in many countries in recent decades has led to increasing interest by researchers and policy-makers in the education to work transition of graduate, and extent to which they can gain employment.

\subsection{The Concept of Employability Defined}

While the concept of employability in higher Education is said to have series of definitions and interpretations in much of the literature available, however, there exists several conceptualizations that can be summarize at more holistic approaches, variously acknowledging labour market and personal characteristics. Rychen et al (2003) describe employability skills as those skills that are directly pertinent to obtaining and maintaining work, while on the other hand, Horrey, (2001), McQuaind and Lindsay (2005) argue that employability skills can be describe as a generic and discipline-specific skill required for performance in a work situation, specifically it comprises of both discipline based and generic skill, which refer to those skills necessary for an individual to develop their fullest potential in an area of study, context or workplace. Because of these numerous perceptions of the term employability skills, there appears to be considerable confusion over how it should be defined and what these skills should look like in a particular discipline. These further resulted into another problem that led to a new call by employers, industries and business organizations such as Business Council of Australia, (2006) for a fresh and systematic approach to developing employability skills, framework that could sustain the agenda.

\subsection{Problem Statement and Purpose of the Study}

There are manifestations of open unemployment all over the world, with very few exceptions. This is evidently clear in the increase in labour forces reflecting high rates of population increase, which also out-space the generation in employment opportunities (Uwaifo, 2009). This is a great tragedy that has continued to be the greatest problem facing several countries particularly the newly developing countries. Their growth fails to provide opportunities for most of students graduating from institution of higher learning and these students fail to mobilize their skills, talents and energies in the moderation process. The crucial question is whether appropriate opportunities can be created through a credible and sustainable employability skills framework for the institutions of higher learning to produce the right graduates with right skills and attitudes that matches the labour market demands. Available statistics compiled by Turnham, rates of open, unemployment in the less developed countries are higher than in the advanced countries and they are especially high for younger graduates. He further shows that these rates are high despite great difficulties in measurement and, that with labour forces growing at 2 to 3 percent a year, even a constant percentage rate of 
unemployment implies a considerable annual growth in the number of unemployment. In a more pessimistic view of Singer, unemployment in the LDCs is already close to 20 to 25 percent of the labour as with 3 to 5 percent in the rich countries and will continue to increase unless counter-influencing trends appear. The consensus is that the reform initiative of school curricula is not a sufficient solution to the problem. For example, the situation of employability in Nigeria has been largely blamed on lack of connecting link by the acquisition of multiple disciplinary skills, between the higher institutions and the employment market. As a result of this, higher institutions continue to fall short on their ability to develop teaching and learning strategies that are appropriate for developing employability skills (Jen, 2002). And the resultant effect of this development provides "skill gap" occurring between the demand of employment and the level of educational preparation of graduates. Indeed, this calls for researches for a common, and effective model or framework of employability that can withstand the test of time of the present day labour market requirement- (Andrew \& Woolen, 2005; Shirpuri \& Kim, 2004; Kivinen \& Silvennoinen, 2002; Morley, 2001; Robison, 2000).

\subsection{Conceptual Issues on Higher Education}

Higher Education has been fingered to play a vital role in achieving development in all ramifications. In many countries, it has provided a dependable leverage for national development, in this regard, education and training have continued to be accorded priority in most countries national development plans in order to educate and prepare enough labour to fill middle and high level positions in the private and public sectors of the economy. This is because the production of sufficient number of tertiary institution graduates with the required skills, knowledge and expertise, necessary for filling the labour market positions, required to promote the modern dynamic economy remains a challenge. Education and training, being an investment capable of yielding benefits that have externalities, is also seen as the main instrument available to government and the community to prepare individuals for a rapidly changing, increasingly demanding world of work and to improve their employability.

The "human capital model or theory" on education which was dominant from the 1950's to the late 1970's / early 1980's made the economists change their view of education from being 'Consumption to Investment'. In other words, education would increase personal capital and by implication, become an investment and a veritable tool used for addressing social problems among others. The human capital mode attempts to explain the link between education and employment and/or supply of skills by educational and training institutions to the labour market. The key premise in this model is that education is an investment which leads to high wages reflecting the increased levels of productivity resulting from human capital accumulation. The mechanism for human capital to impact ability of graduates to participate in the labour market is either due to accumulation of this factor in production or innovation and technological progress resulting from the existing stock of human capital; that is, graduates who have accumulated more educational skill training, and have a higher productivity, should be rewarded with a higher employment probability and wages. This model was subject to all educated people equally. In addition, if more people were able to be educated, there would be an oversupply of well-trained individuals.

Expectedly, all the models available in the area of education, particularly tertiary education are important for national development. They however express radically different prescriptions for how to improve our schools. The differences show up in everything from how to pay and retain good teachers to curriculum design, teaching methods and discipline as well as other germane issues in the context of the study. Urama, (2009) explores the role of higher education for sustainable development innovation in Africa. He explores the emergence of trans-disciplinary sciences, systems thinking and responsible innovation and their implications for education for sustainable development innovations (ESDO in Africa). He argues that current pedagogies and incentive structures in African institutions of higher learning are discipline-based and hence, precludes system thinking, collaboration and responsible innovation which are necessary condition for economic progress as well as social and environment sustainability.

Urama (2009) therefore states that, to make higher education relevant for social, economic and environment sustainability in Africa, a complete re-engineering of our knowledge systems (curriculum design teaching and learning methods, research and development, stakeholder engagement and system of knowledge sharing, dissemination, etc. are urgently required.

\subsection{The Conceptual Framework}

The study describes emergent work from one of the skills research initiative portfolio of research models known as the USEM (2004) account of employability. The framework guided the review and evaluation of the literature, specifically it summarizes the ideas, variables and relationships explored in the previous sections which enable the following questions to be addressed:

1. How has research addressed the multi-level complexities inherent in the phenomenon of employability skills?

2. Which employability initiatives have educational experts studied in recent years?

3. What has been learned about the consequences of employability skills?

For each question, our discussion follows the structure of USEM model (2004) analysis. First we consider the strengths and weaknesses of recent employability research, then we point out opportunities for new research that could further advance our understanding of the dynamics to employability and consider potential threats to continued advancement. The USEM model (Yorke \& Knight, 2004) offered widely accepted defining statement of employability as set of achievements- skills, understanding and personal attributes that makes individuals more likely to gain employment and be successful in their chosen occupations, which benefits themselves, the workforce, 
the community and the economy. That Employability results from a blend of achievements in four broad areas, and is represented as:

- Understanding

- Efficacy beliefs

- Meta-cognition

The model has largely contributed in forming the basic foundation of a large and formidable body of research, however, its inability to assist in explaining to non-experts in the fields particularly the students themselves and their parents what is largely meant by employability is being perceived as a major weakness.

\section{Methods}

After the preliminary literature review, representatives of 18 departments from 6 institutions of higher learning and 3 professionals from 3 companies were interviewed to gather specific data. The key question asked was, what was the possible requirement for graduate employability skills (GES) competencies that will be required to evolve a new model of employability skills (ES) that is sure to capture relevant learning skills, of a particular occupational discipline? While on the other hand, the interview questions were asked about major constraints that impinge on the success and effectiveness of 'GES', and best possible solutions in the approach to develop the skill agenda, views and opinions of both employers and academic staff of higher education were sought, specifically the following questions were asked; the participants were asked to speak freely what they think is the major problem in teaching 'GES'; the best approach to develop 'ES' in higher education (HE); and other learning aspects to be included apart from subject discipline.

\section{Results}

\subsection{Constraints that impinge on the success and effectiveness of GES identified by Academic Staff and Employers}

Many of the Academic Staff and employers observed that lack of conceptual clarity and understanding, Education and job mismatch teaching and learning inadequacies and the need for curriculum change or modification are important and crucial for any attempt that is targeted towards developing an effective and efficient 'GES' programme.

\section{i. It Lacks Conceptual Clarity}

Majority of Academic staff and employers expressed serious concern in the inherent complexities in the skill agenda which consistently undermine several efforts and attempts to initiate any meaningful development of ES, most prominent among these problems or difficulties is in trying to define or interpret the meaning of what ES stand for in reality, other factors ranges from how to measure and develop the skills competencies in the real learning context.

This persistent problem to the views of the majority of employers and academic staff that characterize 'ES' as multidimensional concept and indeed difficult to track was strongly viewed as a serious issue of concern in any attempt towards achieving a viable and successful framework.

\section{ii. Institutional Programmes and Job Requirement Mismatch}

Both the academic staff and employers express their fears on what they describe as increasing gap of; mismatch between educations on the one hand, and employers' expectations of HE on the other hand. The institution's priority in training graduates emphasize more on the honour of degree certificate (academic excellence) whereas the employers are looking for graduates with the ability to exhibit occupational competency and preparedness to the possible challenges that a graduate is likely to come across in the workplace after leaving school. Consequently, the general view based on the situation or position of the academic staff and employers seemingly underpinned by notion of occupations competence or excellence, clearly shows how the key players or stakeholders operate very far apart, at different levels, meaning to say that, one ideology displaces the other, in this case the occupational competency is being displaced by the academic excellence. The reason for such situation as expressed by the employers was due to the fact that the institutions do not welcome interference of what they describe as 'academic freedom', without having to concede or compromise what they believe as right learning content.

\section{iii. Course Content or Curriculum Modification....}

The academic staff including the employers express optimism that introducing new approach to developing 'ES' that cumulatively improves professional graduate 'ES' ability, through the introduction and integrating of new work-ready learning activities into the existing course content of the curriculum that is to say, the curriculum, be redesigned in such a way to accommodate all the relevant and necessary teaching methods and process, and also be expanded to make provisions of more opportunities for skills work experiences. Even though the experts, further opine that overhauling or modification of the curriculum alone may not necessarily translate directly to the production of professional work-ready graduates that can easily find jobs in the labour market, unless other issues relating to the curriculum are addressed and solution proffered. For example, some of the basic problems of tertiary institutions' inability to equip graduates with relevant skills needed for employment is that the curricula are adjudged to be too academic and overloaded with intellectual content at the expense of basic engineering and technology, inadequate provision for humanities, social sciences, business management, concept of entrepreneurship skill development etc. There is also a lack of adequate basic teaching materials such as instructional materials and other laboratory and workshop facilities. There is usually a shortage of highly competent instructors and teaching staff with sufficiently wide range of practical experiences, and above all, the curriculum are based on a foreign model which has evolved under ideal condition that are not easily 
duplicated in developing countries. This suggests the need to overhaul or modify the entire curriculum to be replaced with a new model or framework that is a focus towards developing and succeeding 'GES'.

iv. A new framework could help to solve problem

The academic staff said that their training programmes are based on the occupational needs of the employers. However, they expressed fears that there may be series of problems surrounding the entire skills agenda. Whereas as the employers are saying, we are yet to see graduates that met our requirement, "they come to us with complete credential certifying their academic qualification, indicating they have some skills foundation but we are yet to see them demonstrate those skills in reality. Consequently, we have to organize refresher courses for average period of six month to train and retrain those graduates to learn and relate effectively with our work environment.

The fact that previous experiences indicated that, majority of these graduates are grossly lacking in some basic work skills that are highly needed in all aspect of work life and career. Experts suggests, having a new framework could help solve the problem to address all grey areas, those problems as identified as having potential for significant benefits includes providing a common meaning and interpretation of describing skills related to employability, identify and articulate those skill opportunities a graduate require in line with the employer expectation and making them more visible.

\section{Discussion}

The findings dwelled more on the various constraints that impinge on developing the successful and effective employability skills framework for higher Education. The paper discussed the complexities in the skill agenda which most often has consistently continued to hinder any meaningful progress in the effort to develop employability; this includes defining and interpreting the meaning and what sort of skills represent ES. This persistent problem that characterized 'ES' agenda as multi-dimensional concept and indeed difficult to track was strongly viewed as a serious issue of concern in series of attempts towards developing successful framework. In a related development, from the expressed by the respondents there appears to be a consensus amongst the key stakeholders on the importance of addressing employability within higher Education, however, there remains some arguments on how best this can be achieved, while Little (2003) concludes that there is little evidence of systematic thinking about how best to do it, let alone any model that can be badged as best practice and adopted in the higher Education system. The study indicated that discrepancies existing between the two major stakeholders, that is, institutions that prepare graduates and the potential consumers of such graduates that happened to be the employers of labour has been a major problem that militates against the development of employability skills. The finding clearly indicated that both stakeholders worked or operated in isolation, independent of one another, even though the study indicated that, there are other sources of linkages that are put in place to bridge such gap, however, such links have not been explored judiciously and effectively. This left the institution to continue singlehandedly to develop their programmes of study without any input from Employers, and the consequences' effect of such problems as discovered from the study shows that while institutions have as their priority and of course what they have been preaching or singing is merely to achieve 'academic excellence (honour of degree certificate) which is simply adjudged, only by the number of students who passed written examinations with highly honoured degree certificate at the time of graduation. While on the other hand, the employers are looking forward to having graduates with occupational competency regardless of their grade of degree certificate. The two ideologies held by both stakeholders need to be checked and corrected as this is sure to help in development of the skill agenda. This was supported in an extensive review on patterns of core and generic skills in higher education by Nevelle et al (1999), 'That mismatch between what Universities provide and what employers state they need, appears to rest on ideology and culture of University teaching premised on academic excellence and an employers' perspective seemingly underpinned by notion of what has been called operationalism.

There was a call in the overall for the need for a rethink with a view to address various persistent problems surrounding 'GES' that may lead to the modification of existing curriculum content, in order to come up with a new framework, designed to include all necessary learning activities, that is sure to produce professional work-ready learning outcomes. Both academic staff and employers express optimism that introducing new approach to developing the skill agenda that cumulatively improve professional graduate's skills ability, through the introduction of new work-ready learning activities into the existing course content of the curriculum, will definitely serve as basis towards achieving viable and successful Employable graduates. However, the finding emphasized that such an approach must be designed in such a way to accommodate other relevant and necessary teaching methods, process and procedures which hitherto are not given much attention, the designed Framework must therefore be expanded to make provisions of more opportunities for skills work experiences.

The study further suggests two approaches that that could be used in teaching and learning employability, they are integrated and embedded approach, the two approaches are already in use in most of the tertiary institutions as shown in this study, each has advantages and disadvantages, however, the findings from this study seem to favour embedded approach, given the fact that it is easier to handle and more result oriented in terms of skill development in students' learning. Yorke and Knight, (2004), outline four strategies currently in use within higher Education. These include embedding through the whole curriculum; embedding in the core curriculum; incorporating employability skill within the curriculum; and work-based learning within or parallel with the curriculum.

The findings further suggests that in as much as problems relating to skills acquisition and teaching methods were addressed in the framework through the curriculum, other external factors militating against positive outcome must 
equally be dealt with, this has to do with the curricula being too academic and overloaded with intellectual context instead of basic science, engineering and technology, there is also a lack of adequate basic teaching materials, workshop/laboratory facilities etc. These and many other reasons mentioned earlier suggest the need to overhaul or modify the entire curriculum and if possible be replaced with new model or framework that is more focused towards developing employable and successful graduates.

\subsection{The Proposed Model}

The model developed from this study is presented in Fig. 1. It goes some way towards including the relevant and necessary elements that will ensure graduates achieve an optimum level of Employability skills after graduation from school. The emergent work from one of the skills research initiatives portfolio of research models known as USEM account of employability, guided the review and evaluation of literature in this study. The model consisting of four inter-related components of understanding; skills; efficacy beliefs and metacognition, provides useful overview of the influence on employability and aim to increase the scientific aspect of employability thinking within higher Education (Knight \& Yorke, 2004). However, Knight and Yorke (2004) compiled and provided a list of thirty-nine attributes viewed to be of great importance for ES, for use as applicable in analyzing programmes to facilitate auditing. These attributes falls under three categories of personal qualities, core skills and process skills (see Appendix 'A').

The proposed model depicted in Fig.1 shows the essential element of employability, the framework reflects how these components relate to one another with each representing a particular role, for example, work experience apart from its role as part of career development learning, it may in some cases indicate subject learning relevant to the degree course being studied. The model describe in stages how to provide students with the opportunities to access various employability development opportunities from a particular subject area and reflecting these experiences resulting in the development of a high level of self-efficacy, self-confidence and self-esteem which is considered as important and influential link to employability.

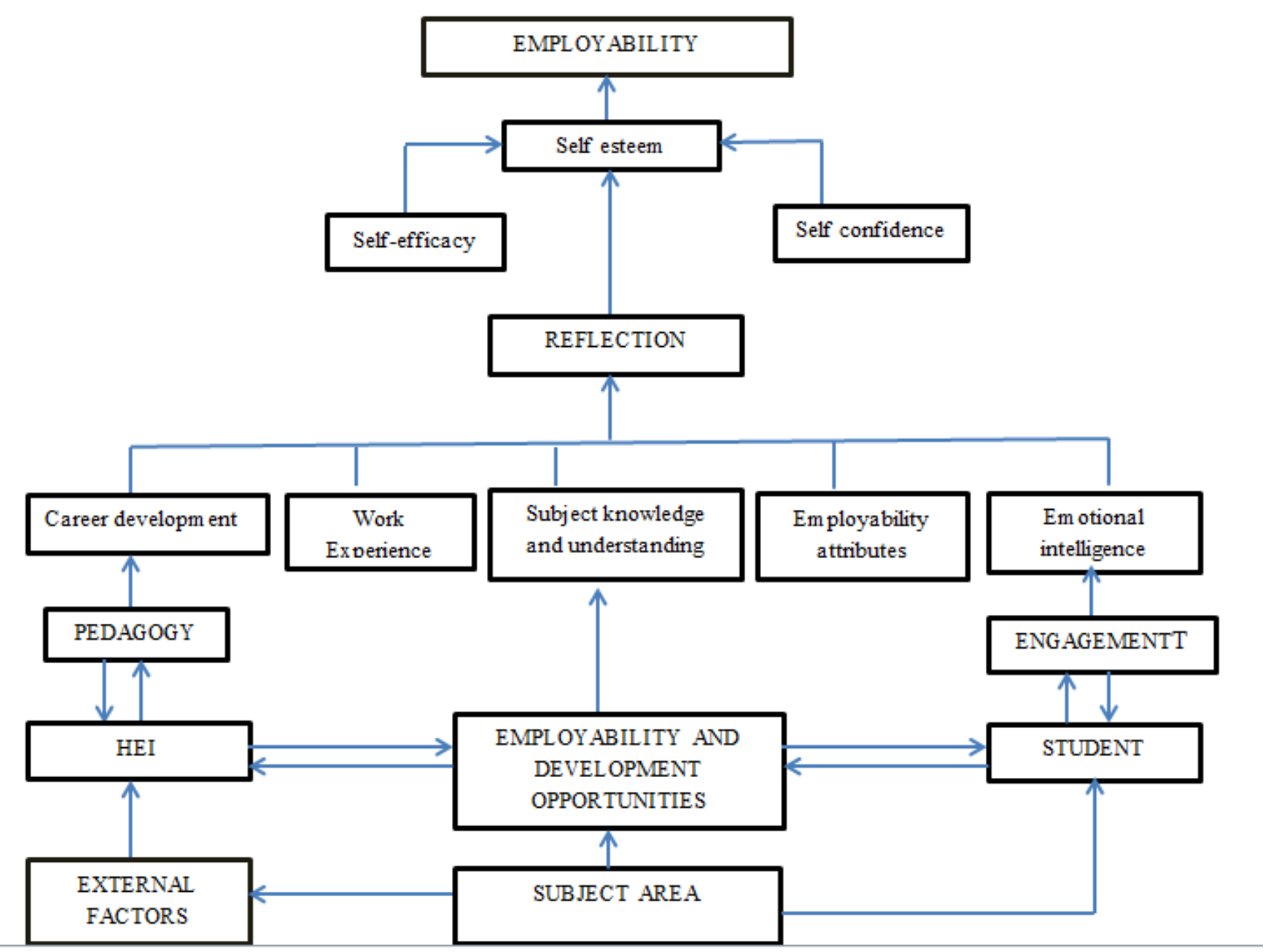

Figure 1. Model of graduate employability skills for Higher Education

\subsection{The Component of the Model}

Subject area: A necessary first step for HE providers in addressing employability is to identify subject area for a particular field from which potential and relevant skills that relate to that particular occupation can be developed taking 
into consideration the external factors such as the entire learning environment that includes teaching facilities, workshop/laboratory, instructional materials, ICT, etc.

Employability and Development Opportunities: From the subject area of study of a particular programme now the institution higher education institutions (HEIs) can now make provision for student learning by embedding in the core curriculum such opportunities for learning. The model lays a greater emphasis on the academic staff having prerequisite pedagogical training and on being well informed current workplace practice and awareness of how such workplace are structured and function. The acquisition of teaching skills by the academic staff as well as knowledge means they are expected to go beyond traditional lecturing and use a range of teaching methods in order to ensure that the students develop such employability opportunities, as subject skill knowledge and understanding; employability attributes or generic skills; emotional intelligence; work experience and career development.

(i) Subject knowledge and understanding skills is being characterized by a specific field of study which a student chooses to study in depth that will in the end earn him or her a high degree qualification that might get him a job (Johnes, 2006). Graduate Prospects 2005/2006, p.17 discovered two-thirds of graduate vacancies as open to graduates of any discipline which implies that for the remaining third, specific knowledge, understanding and skills are still vital and usually employers' considerations for graduates have been on the basis of how successfully they have completed their degree programme. However, these alone are unlikely to secure a graduate occupation in which they can be satisfied and successful.

(ii) Generic skills: In addition to subject-specific skills knowledge and understanding employers are also looking for graduates with well-developed generic skills in a number of areas (Harvey et al 1997). He produced list of generic skills that employers are looking for. This list is provided in appendix 1, pedagogy for employability group (2004)

(iii) Emotional Intelligence: Coleman (1998) define emotional intelligence as

"the capacity for recognizing our own feelings and those of others for motivating ourselves, and for managing emotions well in ourselves and in our relationships"

Emotional intelligence therefore becomes a very crucial component in addition to other components that a graduate may require while undergoing training to achieve or develop his employability potentials. Yorke and Knight (2002) list emotional intelligence as one aspect of employability under personal qualities, but it could be suggested that it subsumes many of the other personal qualities listed and some of the process skills listed too. Several researches have shown that people with levels of emotional intelligence motivate themselves and others to achieve more. Jaeger (2003, p.634) indicated that emotional intelligence can be improved through teaching and learning in higher education setting and is positively correlated with academic achievement.

\section{(iv) Career development learning}

Another important component contained in the model is career development learning; a graduate may require some aspects of their chosen career for them to be successful and become satisfied with it. It is only by so doing that they become aware and develop interest in their chosen career. The aspect of career development learning has not always been presented in its rightful position as it should be in developing employability strategies Watts, (2006), has this to say, career learning involves activities that help students to become self-aware of the occupation they want to do, so as to be able to give real considerations to the things they enjoy doing, this will go a long way to motivating them and also suit their personalities. It also enables them to learn how best to investigate the job markets to see the what opportunities that are available.

\section{(v) Work experience}

Equally of great importance in the effort to develop employability is the work experience. Several research studies have indicated that employers attach greater value in graduate work experience. Work Experience Group (2002) in a research to look at experience opportunities in higher Education found that;

- Employers value people who have undertaken work experience, been able to reflect upon that experience and then go on to articulate on what they have learnt.

- Partnership between employers and education are valuable in promoting work-related learning and in improving the quality and quantity of such experiences.

It is widely believed that graduates with work-experience are more likely secure a job than those without experience. It is also important to consider the wider life experiences that many students, particularly mature students bring with them into higher Education (Pedagogy for Employability Group, 2004). This component therefore emphasize the need for students to be guided with all the necessary information in how life experience and work-related experience either arranged as part of a course of study, taught through the curriculum or other means for the purpose of enhancing their employability. 
(vi) Reflection and evaluation:

Including reflection and evaluation in this model became very crucial and important because the students having acquired necessary skills, knowledge understanding and relevant attributes also needed opportunities for reflection and evaluation of such learning experiences that have already taken place. Students are not likely to give full consideration to how far they have come in developing their employability and what they may need to do in order to develop it further.

\section{(vii)Self-efficacy/self-confidence/self-esteem}

These three components are closely inter-related; they are crucial in the provision of employability because it provides a link between knowledge, understanding, skills experience and personal attributes that lead to enhance employability. Badura (1995, p.2) refers to self-efficacy as beliefs in ones capabilities to organize and execute the course of actions required to manage prospective situations. Efficacy beliefs influence how people think, feel, motivate themselves and act. And suggested further a number of sources of efficacy beliefs, those relevant to employability include mastery experiences, vicarious experiences provided by social models and social persuasions. Mastery experience occurs when people are given the opportunity to try a particular task themselves. For examples of mastery experiences within the employability agenda are work experiences, and realistic work environment (as provided by the centre for employability through the humanities at UCLan where students get the chance to be involved with activities such as publishing, theatre performance etc). Badura (1995) points out that mastery experiences are the most effective way of creating a strong sense of self-efficacy that plays a vital role within employability.

Vicarious experiences, provided by social models occur when students are able to see others who achieved success. The closer the others are in similarity to themselves, the more effective the experiences are. Examples of these are when successful recent graduates return to the University to give talks to current students about how they achieved their goals.

Whereas social persuasions, on the other hand, occurs when people are persuaded that they possess the capabilities needed to master a particular activity. This encourages them to put more effort and stay motivated in order to achieve success in their goals. Therefore, by providing the opportunities for master experiences, vicarious experiences and social persuasions, then encouraging reflection and evaluation of these experiences, and self-efficacy can be increased. Graduates who believe they can do whatever is necessary is far more likely to a position and be successful in whatever occupation they choose than graduates who do not have those self-beliefs (Dacrepool et al, 2007).

Self- confidence; while self-efficacy is seen as a belief that one has the capability in particular situation, then self-confidence could be seen as the way this is projected to the outside world. It appears to be something that can be seen from a person's manner and behavior. Individuals with self- confidence are able to present themselves with self-assurance and have presence. Coleman (1998) and Norman and Hyland, (2003) suggest that if self-confidence is seen as a trait, which personality theorists suggest are relatively stable over time, then those who lack self-confidence would be unlikely to develop it through educational creativity.

Whereas self-esteem on the other hand, has to do with self-respect and a feeling of worthiness, people that are realistic in their evaluations of themselves. Without this realism a person is unlikely to reflect on areas for improvement which is crucial to the lifelong learning. Lawrence (1996) supports the inclusion of selfesteem in the model:

"one of most exciting discoveries in educational psychology in recent times has

been the people's levels of achievement are influenced by how they feel about

themselves. A vast body of research evidence has accumulated showing a positive

correlation between self-esteem and achievement."

This suggested that increased self-esteem becomes major part of the key to employability because by achieving a high level of self-esteem, a graduate will also be realistic about their achievements and be committed to lifelong learning.

\subsection{The Value of the Model}

The new model and its components discussed in the previous section have provided details of how it will be useful in addition to the existing literature, on the development of employability particularly in the institutions of higher learning; most importantly, it is hoped that the outcome will lead to establishing a common higher education programme or curricula that is work-based, dynamic, explicit in its outcomes, fully articulated, realistic, and skill experience oriented that will no doubt encourage students to think about work-place learning more explicitly and reflectively. This will in turn directly help students to develop a broad range of knowledge, skills, attitudes and values each of which ultimately contribute to the evolution and growth of knowledge on the linkage between higher education and workplace. 


\section{References}

Uwaifo, V. O. (2009). Technical Education and its challenges in Nigeria in the $21^{\text {st }}$ Century International NGO Journal Vol. 51(2), 40-44

Marlin, C. (2007) Understanding and meaning of employability in changing career contexts journal of European Industrial Training Vol. 3(4), 258-284

Burk, R.J. and Ng, E. (2006). The changing nature of an organization: Implications for human resource management. Human Resources Management Review, 16, 86-94.

Richardson, S. (2006). What is a skill shortage? National Institute of labour studies, Flinders University, Adelaide.

Rychen, D.S., \& Salgarik, L. H., (2003). Key competences for a successful life and a well- functioning society. Gottingen, Germany; Hogrefe \& Huber.

Mc Quaid, R.W. and Lindsay, C. (2005) “The concept of employability”. Urban Studies, The Annals of Regional Science, Vol. 40 Pp. 407-21

Business Council of Australia, (2006). New concepts in innovation: the keys to a growing Australia: Melbourne: Author.

Jen, S.U. (2002), Issues and Constraints in Polytechnic Education in Nigeria: Paraclete Publishers, Yola- Nigeria.

Andrew, K. \& Woolen, B. (2005). Closing the Gap: Helping students identify the skills Employers want. National Association of Colleges and Employers Journal, 65 (4), 40-43

Shirpuri, S. \& Kim, B. (2004). Do employers and colleges see eye-to-eye? National Association of Colleges and employers, $37-44$.

Robinson, J. P. (2000). What are employability skills? The workplace 5 (3) 1-3 Retrieved September 9, 2005, from http://www.aces.edu/crd/workforce/publications/employability- skills-pdf

Morley, L. (2001). Producing new workers: quality, equality and employability in higher education, quality in higher education 7 (2), $131-138$.

Kivinen, O. \& Silvennoinen, H. (2002). Changing relations between education and work on the mechanisms and outcomes of the educational system, international journal of lifelong education, 2 (1), 44 -54

Urama, K. C. (20090. Higher Education for Sustainable Development in Nigeria (HESDA) Africa Technology Policy Studies Network, Nairobi, Kenya.

Yorke, M. \& Knight, P. (2007). Evidence-informed pedagogy and the enhancement of student employability teaching in higher education $12(2), 157-170$

Little, B. (2003) International perspectives on employability. Briefing paper, York, the Higher Education Academy. Availble online at http://www.heacademy.ac.uk/ accessed 21 March, 2005.

Yorke, M. \& Knight, P. (2004). Learning, curriculum and employability in Higher Education London: Routledge Falmer.

Johnes, G. (2006). "Career interruptions and labour market outcomes”, EOC working paper series, No. 45, Equal Opportunities Commission, Manchester.

Harvey, L. Moon, S. and Geall, V. (1997). The Graduates work: organizational change and students attributes. Centre for Research into Quality. University of Central England, Birmingham.

Pedagogy for Employability, learning and Employability series ESECT: The Higher Education Academy.

Yorke, M. \& Knight, P.I. (2002). Employability through the curriculum, skills plus: turning the undergraduate curriculum, June 2002 edition.

Jaeger, A.J. (2003). Job competencies and the curriculum an inquiry into emotional intelligence in graduate professional education. Research in Higher Education, 44 (6), 615 - 639

Watts, A. G., (2006): Career Development learning and employability in Higher Education, a competency approach. Quality in Higher Education. 7 (3) 191 -198

Work Experience Group, (2002). Work related learning Report, DFES Publications, Nottingham

Badura, A. (1995). Exercise of personal and collective efficacy in changing societies." In Badura, A. (Ed), selfefficiency in changing society of Australia.

Dacrepool, L. \& Sewell P. (2007). The key to employability Developing a practical model of graduate employability Education + Training, 49(4), 227- 289

Norman, M. \& Hyland, T. (2003). The role of confidence in lifelong learning “: Educational studies”, 29(2/3), 261 -272

Lawrence, D. (1996). Enhancing self-esteem in the classroom, $2^{\text {nd }}$ ed. Paul Chapman, London.

Olaitan, S. O. (1996). Vocational and Technical Education in Nigeri (Issues and Analysis) Onitsha. Noble Graphics Press.

Okoro, O. M., (1994) Principles and Methods of Vocational and Technical Education, Enugu Abic Publishers. 
Yabain, A. M. (1990). The Polytechnic concept: Adoption, Implementation and future perspective in Nigeria. Paper presented at the $10^{\text {th }}$ Annual national training conference of the National Vocational Association at Umunze, Nigeria.

Njoku, C. U. (1997). An appraisal of the Business Education Programme in selected Tertiary and vocational institutions in Nigeria unpublished Ph.D. Thesis University of Nigeria, Nsukka.

Abubakar, M. S. (2000). The challenges of Revitalizing the Polytechnic curriculum, paper presented at the $2^{\text {nd }}$ National seminar on strategies for updating and modernizing science and Technology Education held on $8^{\text {th }}-11^{\text {th }}$ August at I.M.T. Enugu, Nigeria.

Federal Republic of Nigeria (1998). National Policy on Education (Rev.) Lagos, Federal Government Press

Coleman, D. (1998) Working with Emotional Intelligence, Bloomsbury, London.

\section{APPENDIX A Aspects of Employability (Yorke and Knight, 2004: 22)}

\section{A. PERSONAL QUALITIES}

1. Malleable self theory: belief that attributes (e.g. intelligence) are not fixed and can be developed

2. Self-awareness: awareness of own strengths and weaknesses, aims and values

3. Self-confidence: confidence in dealing with the challenges in employment and life

4. Independence: ability to work without supervision

5. Emotional intelligence: sensitivity to others' emotions and the effects they can have

6. Adaptability: ability to respond positively to changing circumstances and new challenges

7. Stress tolerance: ability to retain effectiveness under pressure

8. Initiative: ability to take action unprompted

9. Willingness to learn: commitment to ongoing learning to meet the needs of employment and life

10. Reflectiveness: the disposition to reflect evaluatively on the performance of oneself and others

\section{B. CORE SKILLS}

11. Reading effectiveness: the recognition and retention of key points

12. Numeracy: ability to use numbers at an appropriate level of accuracy

13. Information retrieval: ability to access different information sources

14. Language skills: possession of more than a single language

15. Self-management: ability to work in an efficient and structured manner

16. Critical analysis: ability to 'deconstruct' a problem or situation

17. Creativity: ability to be original or inventive and to apply lateral thinking

18. Listening: focused attention in which key points are recognized

19. Written communication: clear reports, letters, etc., written specifically for the reader

20. Oral presentations: clear and confident presentation of information to a group

21. Explaining: orally and in writing

22. Global awareness: in terms of both cultures and economics

\section{PROCESS SKILLS}

23. Computer literacy: ability to use a range of software

24. Commercial awareness: understanding of business issues and priorities

25. Political sensitivity: appreciates how organisations actually work and acts accordingly

26. Ability to work cross-culturally: both within and beyond UK

27. Ethical sensitivity: appreciates ethical aspects of employment and acts accordingly

28. Prioritizing: ability to rank tasks according to importance

29. Planning: setting of achievable goals and structuring action

30. Applying subject understanding: use of disciplinary understanding from HE programme (e.g. marketing, finance, human resource mgmt. etc)

31. Acting morally: has a moral code and acts accordingly

32. Coping with ambiguity and complexity: ability to handle ambiguous and complex situations

33. Problem-solving: selection and use of appropriate methods to find solutions

34. Influencing: convincing others of the validity of one's point of view

35. Arguing for and/or justifying a point of view or a course of action

36. Resolving conflict: both intra-personally and in relationships with others

37. Decision making: choice of the best option from a range of alternatives

38. Negotiating: discussion to achieve mutually satisfactory resolution of contentious issues

39. Teamwork: can work constructively with others on a common task 